Article

\title{
Excellent Electrocatalytic Hydrogen Evolution Reaction Performances of Partially Graphitized Activated-Carbon Nanobundles Derived from Biomass Human Hair Wastes
}

\author{
Sankar Sekar ${ }^{1,2} \mathbb{D}$, Dae Hyun Sim ${ }^{1,2}$ and Sejoon Lee ${ }^{1,2, *(\mathbb{D})}$ \\ 1 Department of Semiconductor Science, Dongguk University-Seoul, Seoul 04620, Korea; \\ sanssekar@gmail.com (S.S.); gee04143@hanmail.net (D.H.S.) \\ 2 Quantum-Functional Semiconductor Research Center, Dongguk University-Seoul, Seoul 04620, Korea \\ * Correspondence: sejoon@dongguk.edu
}

check for

updates

Citation: Sekar, S.; Sim, D.H.; Lee, S. Excellent Electrocatalytic Hydrogen Evolution Reaction Performances of Partially Graphitized ActivatedCarbon Nanobundles Derived from Biomass Human Hair Wastes.

Nanomaterials 2022, 12, 531. https:// doi.org/10.3390/nano12030531

Academic Editor: Toshihiro Shimada

Received: 7 January 2022

Accepted: 29 January 2022

Published: 3 February 2022

Publisher's Note: MDPI stays neutral with regard to jurisdictional claims in published maps and institutional affiliations.

Copyright: (c) 2022 by the authors. Licensee MDPI, Basel, Switzerland. This article is an open access article distributed under the terms and conditions of the Creative Commons Attribution (CC BY) license (https:// creativecommons.org/licenses/by/ $4.0 /)$.

\begin{abstract}
Carbonaceous materials play a vital role as an appropriate catalyst for electrocatalytic hydrogen production. Aiming at realizing the highly efficient hydrogen evolution reaction (HER), the partially graphitized activated-carbon nanobundles were synthesized as a high-performance HER electrocatalyst by using biomass human hair ashes through the high-temperature $\mathrm{KOH}$ activation at two different temperatures of 600 and $700{ }^{\circ} \mathrm{C}$. Due to the partial graphitization, the $700{ }^{\circ} \mathrm{C} \mathrm{KOH}-$ activated partially graphitized activated-carbon nanobundles exhibited higher electrical conductivity as well as higher textural porosity than those of the amorphous activated-carbon nanobundles that had been prepared by the $\mathrm{KOH}$ activation at $600{ }^{\circ} \mathrm{C}$. As a consequence, the $700^{\circ} \mathrm{C}$-activated partially graphitized activated-carbon nanobundles showed the extraordinarily high HER activity with the very low overpotential $\left(\approx 16 \mathrm{mV}\right.$ at $10 \mathrm{~mA} / \mathrm{cm}^{2}$ in $\left.0.5 \mathrm{M} \mathrm{H}_{2} \mathrm{SO}_{4}\right)$ and the small Tafel slope $(\approx 51 \mathrm{mV} / \mathrm{dec})$. These results suggest that the human hair-derived partially graphitized activatedcarbon nanobundles can be effectively utilized as a high-performance HER electrocatalyst in future hydrogen-energy technology.
\end{abstract}

Keywords: biomass; activated carbon; nanobundles; electrocatalysts; hydrogen evolution reaction

\section{Introduction}

Hydrogen $\left(\mathrm{H}_{2}\right)$ has garnered tremendous attention because of its high energy efficiency, sustainability, recyclability, zero carbon emission, eco-friendliness, and alternativeness for fossil fuels [1-4]. For highly efficient and renewable hydrogen production, the hydrogen evolution reaction (HER) is of great importance [5-9]. In general, platinum (Pt)-based alloys are typically used as a HER electrocatalyst. However, both the low availability and the high cost of Pt have restricted its wide applications [10]. To realize future green and clean hydrogen energy technology, therefore, developing the low-cost and highly efficient HER electrocatalyst is essential. In recent years, various carbonaceous materials (e.g., graphene [11,12], activated carbon [13-16], graphene oxide [17], carbon nanotube [18-21], graphitic carbon [22], porous carbon [23,24], carbon fiber [25], etc.) have been studied in order to find an appropriate HER electrocatalyst that can replace the Pt alloys [26]. Among them, biomass activated carbon (AC) has become one of the adequate candidates as a HER electrocatalyst because of its high porosity, high conductivity, large surface area, high durability, high abundance, cost-effectiveness, and environmental friendliness $[5,20,27]$. For instance, Saravanan et al. [14] synthesized the AC nanosheets from peanut shells through the $\mathrm{KOH}$ activation, and they achieved an over potential of $80 \mathrm{mV}$ at $10 \mathrm{~mA} / \mathrm{cm}^{2}$ and a Tafel slope of $75 \mathrm{mV} / \mathrm{dec}$. Prabu et al. [15] used the Ooty Varkey food wastes to derive the nanoporous $\mathrm{AC}$ sheets, possessing a good HER activity with a low overpotential of $380 \mathrm{mV}$ at $10 \mathrm{~mA} / \mathrm{cm}^{2}$ and a Tafel slope of $85 \mathrm{mV} /$ dec. In addition, Liu et al. [24] prepared the $\mathrm{N}$ - and S-codoped porous carbon nanosheets by using human hair through 
the $\mathrm{ZnCl}_{2}$ activation at nitrogen atmosphere, and the nanosheets showed the outstanding HER characteristics with a low overpotential of $12 \mathrm{mV}$ and a Tafel slope of $57.4 \mathrm{mV} / \mathrm{dec}$ at $10 \mathrm{~mA} / \mathrm{cm}^{2}$. Among various biomass resources, because of its large carbon contents ( $>51 \%$ [28]), human hair can be utilized as an effective precursor for the derivation of carbon resources. Therefore, the reuse of the abundant biomass human hair wastes can be of superior benefit to fabricate the high-performance AC nanostructures. According to our best survey, however, the HER performance of human hair-derived activated carbon (HH-AC) has rarely been studied, except for a previous work by Liu's group [24].

In light of these backgrounds, we investigated the facile and cost-effective synthesis of the partially graphitized mesoporous AC nanobundles by using biomass $\mathrm{HH}$ via the hightemperature $\mathrm{KOH}$ activation and characterized their structural, morphological, textural, and electrocatalytic properties. Herein, we report on the state-of-the-art HER activities of the $\mathrm{HH}$-AC layered-nanobundles (i.e., extremely low overpotential of $\sim 16 \mathrm{mV}$ at $10 \mathrm{~mA} / \mathrm{cm}^{2}$ in $0.5 \mathrm{M} \mathrm{H}_{2} \mathrm{SO}_{4}$ and a very small Tafel slope of $\sim 51 \mathrm{mV} / \mathrm{dec}$ ).

\section{Experimental Section}

\subsection{Synthesis of $H H-A C$ Nanobundles}

Figure 1 schematically illustrates the experimental procedure for the synthesis of biomass HH-AC. The biomass carbonaceous resource of $\mathrm{HH}(100 \mathrm{~g})$ was collected from the lead authors participated in this work. Firstly, a bundle of $\mathrm{HH}$ was cleaned in deionized (DI) water and dried in air atmosphere during $12 \mathrm{~h}$. To obtain the carbonaceous precursors, thereafter, DI-cleaned $\mathrm{HH}$ was carbonized at $300{ }^{\circ} \mathrm{C}$ for $1 \mathrm{~h}$ in air. Subsequently, $3 \mathrm{~g}$ of $\mathrm{HH}$-carbonized ash (HHA) was mixed with $12 \mathrm{~g}$ of $\mathrm{KOH}$ (Sigma Aldrich, Seoul, Korea) in a ceramic mortar and annealed at two different temperatures of 600 and $700{ }^{\circ} \mathrm{C}$ for $2 \mathrm{~h}$ in air. After the $\mathrm{KOH}$ activation, the mixture of $\mathrm{KOH}-\mathrm{HHA}$ was soaked in $100 \mathrm{~mL}$ DI water for $10 \mathrm{~h}$ to remove the potassium-based precipitates.

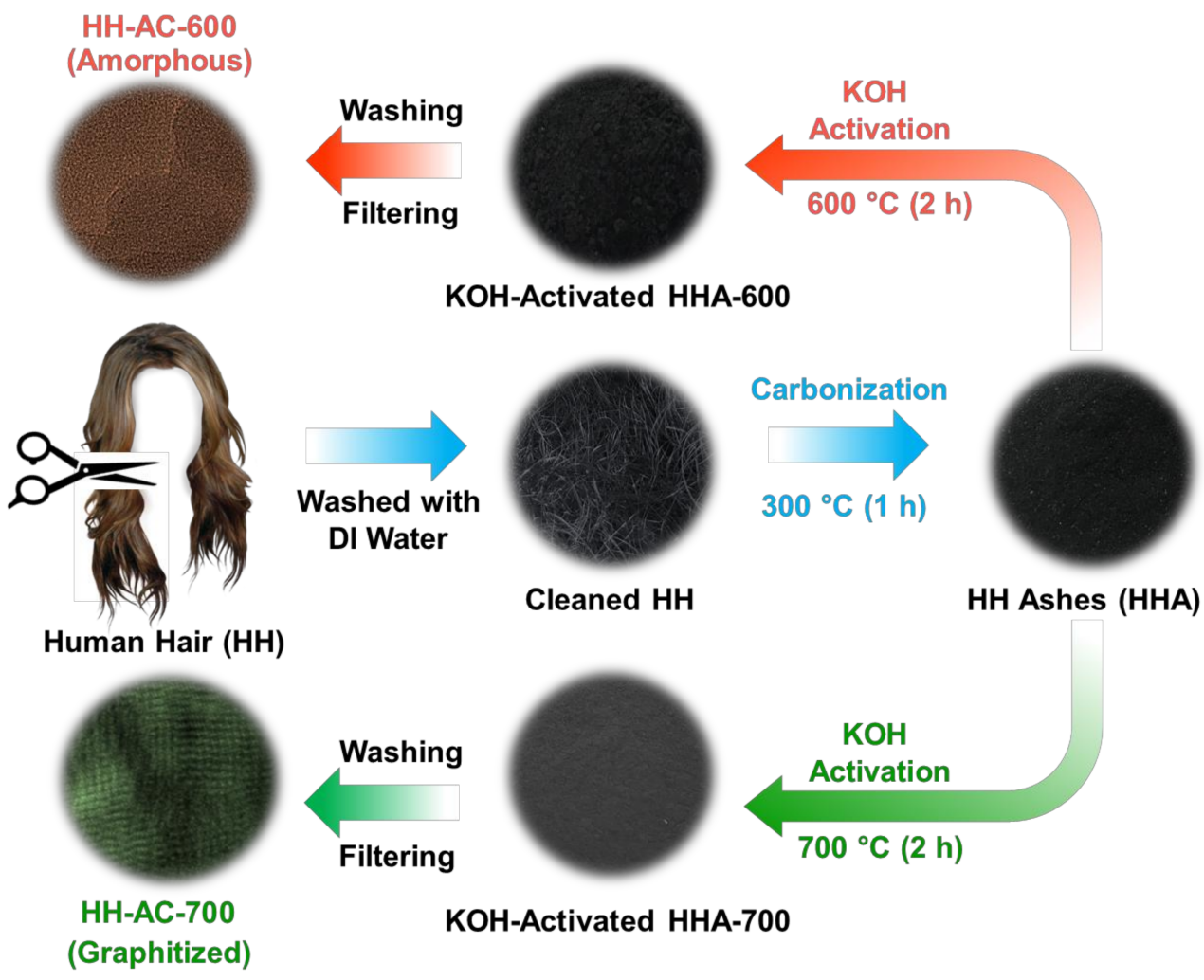

Figure 1. Schematic illustration of the synthesis process for the HH-AC-600 nanobundles and the HH-AC-700 layered nanobundles. 
Finally, the powder types of amorphous $\mathrm{HH}-\mathrm{AC}\left(\mathrm{KOH}\right.$-activated at $\left.600{ }^{\circ} \mathrm{C}\right)$ and graphitized $\mathrm{HH}-\mathrm{AC}\left(\mathrm{KOH}\right.$-activated at $\left.700{ }^{\circ} \mathrm{C}\right)$ were collected, filtered, washed, and dried at $150{ }^{\circ} \mathrm{C}$ for $8 \mathrm{~h}$. For convenience, we denoted the former and the latter as 'HH-AC-600' and 'HH-AC-700', respectively.

\subsection{Material Characterizations}

The morphological and compositional properties of the HH-AC-600 and HH-AC-700 samples were assessed through the field-emission scanning-electron microscopy (FE-SEM) and in situ energy dispersive X-ray (EDX) spectroscopy measurements, respectively, by using an Inspect-F50 system (FEI, Mahwah, NJ, USA). Additionally, the microstructural properties of the samples were further investigated through the transmission electron microscopy (TEM) and in situ selective-area electron diffraction (SAED) measurements by using a JEM 2100F system (JEOL, Tokyo, Japan). The crystallographic and the vibrational characteristics were analyzed by the X-ray diffraction (XRD) and Raman scattering spectroscopy measurements, respectively, by using a D8-Advance system (Bruker, Madison, WI, USA) and a LabRAM HR800 system (Jobin Yvon, Longjumeau, France). The textural properties of the samples were examined via the Brunauer-Emmett-Teller (BET) and Barrett-Joyner-Halenda (BJH) analysis methods by using a BELSORP-mini II equipment (MicrotracBEL, Osaka, Japan). To gain a reliability of the materials characterization, for all measurements, we carried out at least three runs by using multiple samples that were fabricated by the identical synthesis processes.

\subsection{Electrocatalytic Measurements}

To characterize the electrocatalytic performances of HH-AC-600 and HH-AC-700, as a primary task, the working electrodes were fabricated by using the HH-AC-600 and HH-AC-700 samples. First, activated carbon (e.g., either HH-AC-600 or HH-AC-700) was added into the N-methyl-2-pyrrolidinone solution. Then, the mixture slurries were coated on the stainless steel substrates $\left(1 \mathrm{~cm}^{2}\right)$ and dried at $150{ }^{\circ} \mathrm{C}$ for $8 \mathrm{~h}$. In addition, the saturated calomel electrodes (SCE) and the platinum meshes were used as a reference electrode and a counter electrode, respectively. The HER activity of the HH-AC-600 and $\mathrm{HH}-$ AC-700 electrocatalysts were investigated by linear sweep voltammetry (LSV) and cyclic voltammetry $(\mathrm{CV})$ via the three-electrode method using a VersaSTAT-3 electrochemical workstation (Ametek Scientific Instruments, Berwyn, PA, USA). The CV measurements were carried out under various potential scan rates from 10 to $100 \mathrm{mV} / \mathrm{s}$ within a potential window of $0-0.8 \mathrm{~V}$. The LSV measurements were performed in a $0.5 \mathrm{M} \mathrm{H}_{2} \mathrm{SO}_{4}$ electrolyte solution under the constant potential scan rate of $5 \mathrm{mV} / \mathrm{s}$. The electrochemical impedance spectroscopy (EIS) measurements were conducted at a frequency range of $1 \mathrm{~Hz}-10 \mathrm{kHz}$. In $0.5 \mathrm{M} \mathrm{H}_{2} \mathrm{SO}_{4}$, the overpotential $(\eta)$ and the Tafel slope $\left(S_{T}\right)$ were determined by using the equations below:

$$
\begin{gathered}
\mathrm{E}_{R H E}=\mathrm{E}_{S C E}+0.26 \mathrm{~V} \\
\eta=\mathrm{S}_{T} \log (J)+c
\end{gathered}
$$

where $\mathrm{E}_{R H E}$ and $\mathrm{E}_{S C E}$ are the standard potential values of the reversible hydrogen electrode and the saturated calomel electrode, respectively. $c$ is the fitting parameter.

\section{Results and Discussion}

Figure 2 shows the FE-SEM images of the HH-AC-600 and HH-AC-700 samples. The $\mathrm{HH}-\mathrm{AC}-600$ sample displays the nanobundles-aggregated morphology (Figure 2a-c). Similarly, the HH-AC-700 sample also exhibits the aggregated nanobundles-like morphology (Figure 2d-f). In the case of $\mathrm{HH}-\mathrm{AC}-700$, however, the layered texture became clearer than HH-AC-600. From the EDX analysis, both samples were confirmed to contain only their main species of C (see Figure S1, Supplementary Materials). The microstructural insights of the HH-AC-600 and the HH-AC-700 samples were further monitored by TEM. As shown in Figure 3a, HH-AC-600 reveals the aggregated nanobundles-like structure. From the high- 
resolution TEM images (Figure 3b,c) and the SAED pattern (Figure 3d), one can specify that the $\mathrm{HH}-\mathrm{AC}-600$ nanobundles are amorphous. In the case of $\mathrm{HH}-\mathrm{AC}-700$, the aggregated nanobundles are also observable from its bright-field TEM image (Figure 3e). Differently from HH-AC-600, however, the stacked/layered nanobundles are much more clearly visible. The average thickness of the layered nanobundle stack is $20 \mathrm{~nm}$. Here, it should be noticed that the layered HH-AC-700 nanobundles display the partially graphitized crystallites, although some parts still remain amorphous (Figure 3f). The lattice spacing of the crystallite is $0.34 \mathrm{~nm}$ (Figure $3 \mathrm{~g}$ ); and the lattice planes of the crystallites are (002) and (100), as depicted in the SAED pattern (Figure $3 \mathrm{~h}$ ).
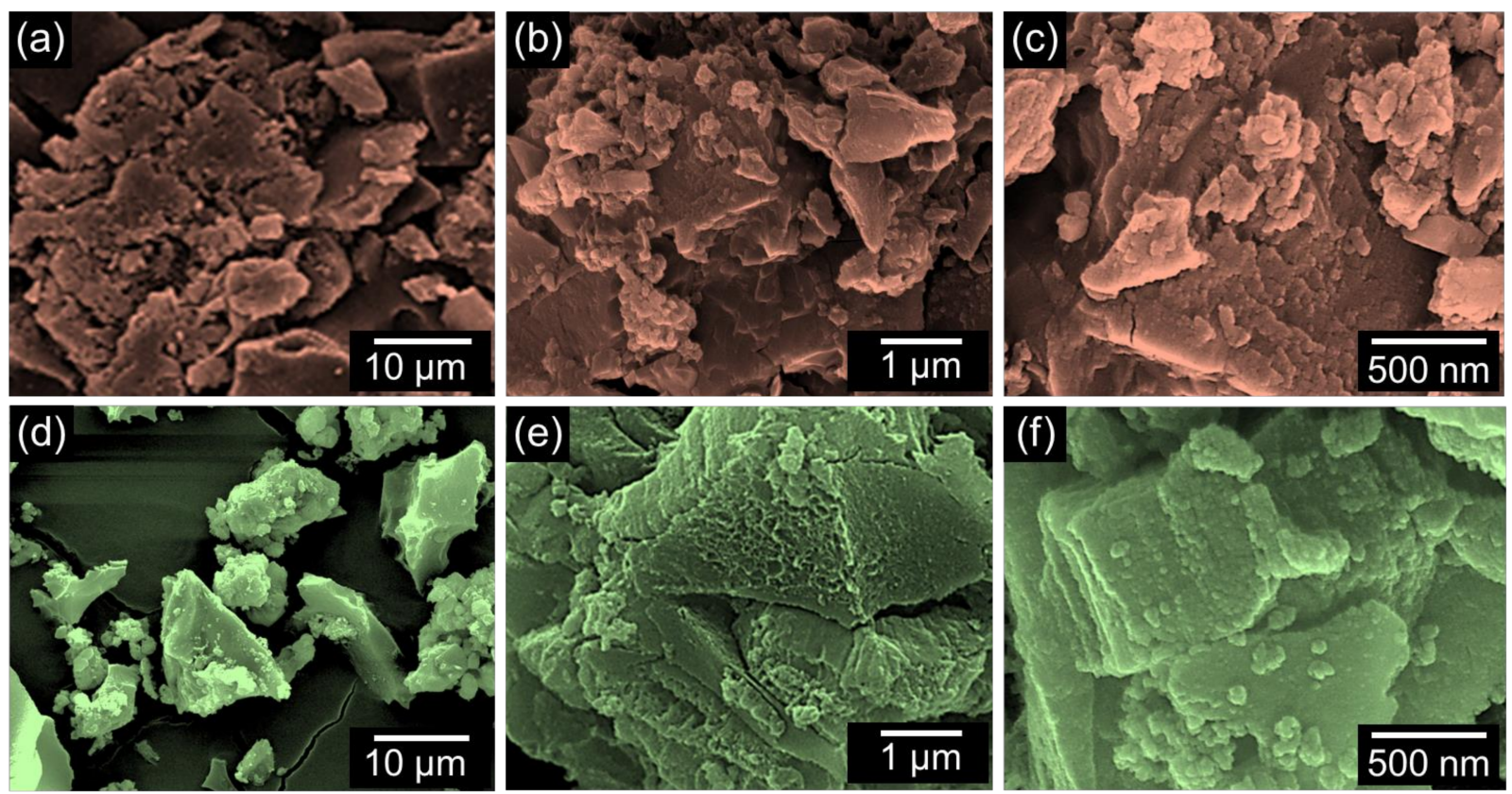

Figure 2. FE-SEM images of (a-c) HH-AC-600 and (d-f) HH-AC-700.
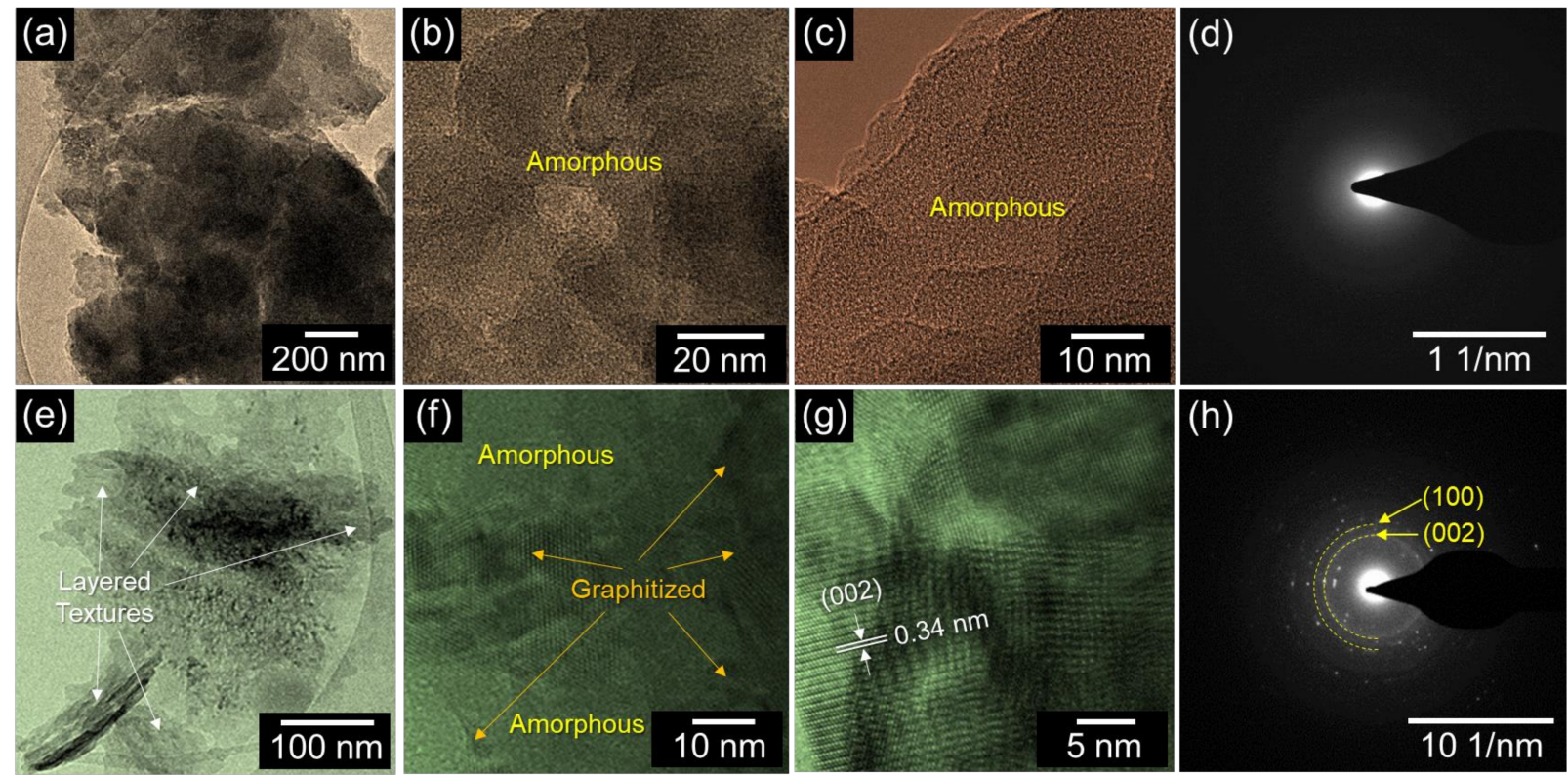

Figure 3. (a) Bright-field TEM image, (b,c) high-resolution TEM images, and (d) SAED pattern of HH-AC-600; (e) bright-field TEM image, (f,g) high-resolution TEM images, and (h) SAED patterns of HH-AC-700. 
Next, the crystallographic properties of HH-AC-600 and HH-AC-700 were examined by XRD. As shown in Figure $4 \mathrm{a}$, the samples reveal a wide diffraction pattern at the Bragg angle at $24.8^{\circ}$ with a small Bragg pattern at $42.6^{\circ}$. The former and the latter correspond to the (002) and the (100) lattice planes of the disordered carbon structure [29-31], respectively. For the HH-AC-700 nanobundles, the (100) intensity is much stronger than that of the HH-AC-600 nanobundles. This infers that the HH-AC-700 nanobundles contain a high density of pores exclusive to the solid-state graphitic carbon [32,33]. These results indicate that the HH-AC-700 nanobundles have a good quality for the electrocatalysts electrode material (e.g., high surface area, high porosity, high conductivity, etc.).

(a)

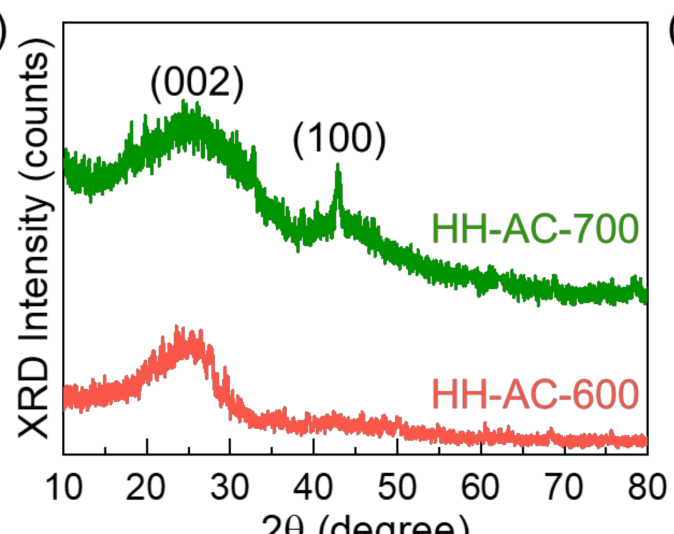

(b)

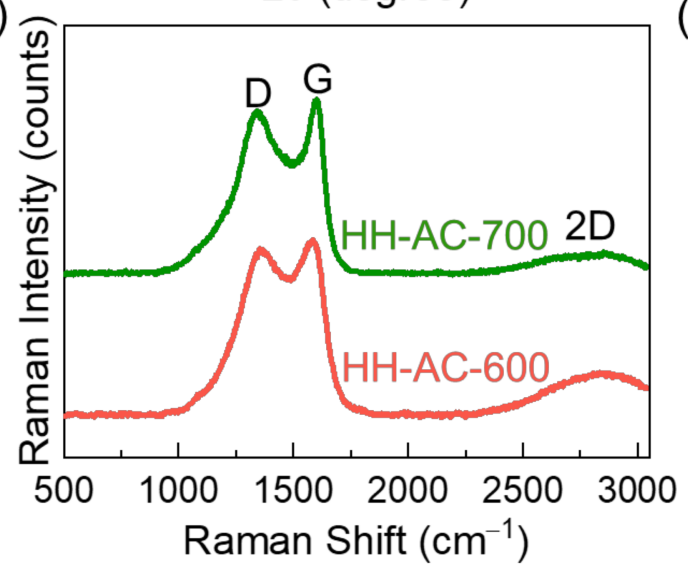

(c)

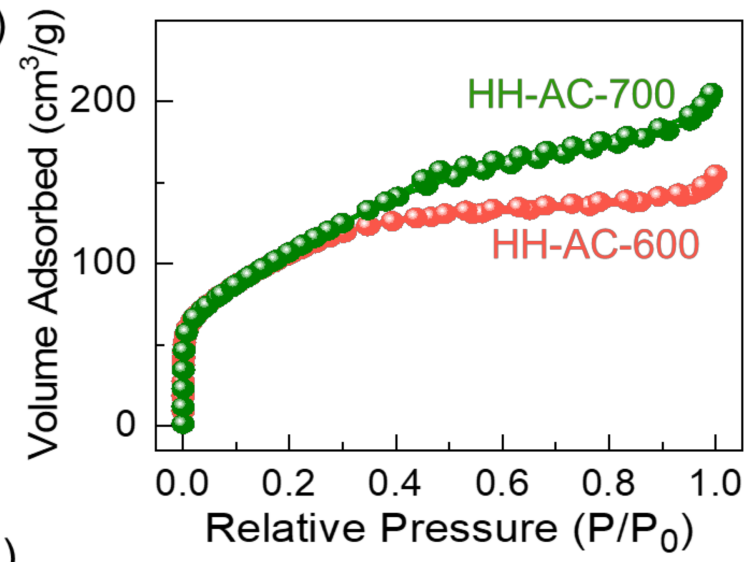

(d)

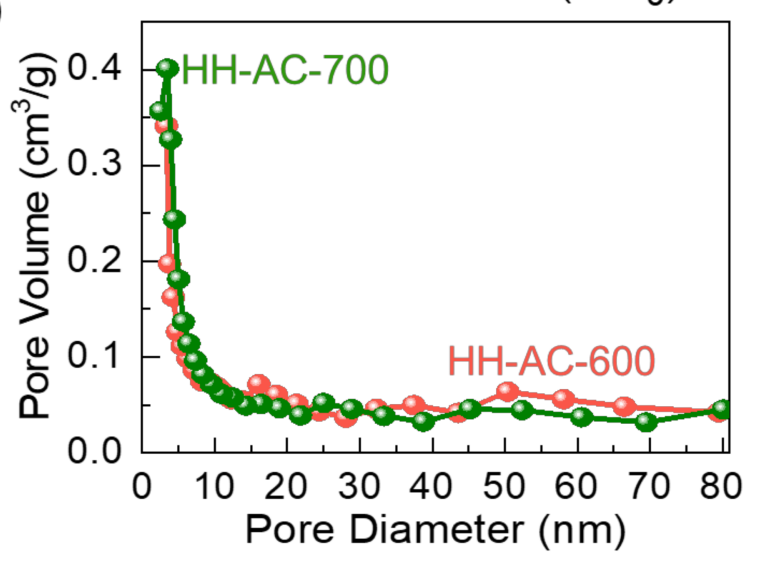

Figure 4. (a) XRD patterns, (b) Raman spectra, (c) $\mathrm{N}_{2}$ adsorption-desorption isotherm characteristics, and (d) pore size distribution characteristics of HH-AC-600 and HH-AC-700.

The graphitic nature was further elucidated by the Raman scattering spectroscopy measurements. Both HH-AC-600 and HH-AC-700 samples display three predominant Raman bands at $2848 \mathrm{~cm}^{-1}$ (2D band), $1601 \mathrm{~cm}^{-1}$ (G band), and $1345 \mathrm{~cm}^{-1}$ (D band) (Figure $4 \mathrm{~b}$ ). The $2 \mathrm{D}$ band is indicative of the distinctive signature from the activated carbon; and the $G$ and the $D$ bands are attributed to the $E_{2 g}$ vibration mode of the $\mathrm{sp}^{2}$ hybridized carbon and the disorder vibration mode of graphitic carbon, respectively [34-36]. According to previous reports [29], the $\mathrm{I}_{\mathrm{D}} / \mathrm{I}_{\mathrm{G}}$ ratio represents the degree of graphitization for the layered carbonaceous materials. The $\mathrm{I}_{\mathrm{D}} / \mathrm{I}_{\mathrm{G}}$ ratio was determined to be 0.96 and 0.93 for HH-AC-600 and HH-AC-700, respectively. Therefore, one can conjecture that, in comparison with the amorphous HH-AC-600 nanobundles, the partially graphitized $\mathrm{HH}-\mathrm{AC}-700$ nanobundles have a higher degree of graphitization and a lower degree of the disordered lattice configuration.

The graphitization of AC would strongly affect the porosity of the entire material system because the local recrystallization at the high temperature gives rise to the increase in structural faults and voids at both the crystallite interfaces and the grain boundaries 
inside the partially crystallized solid-state material system (i.e., polycrystalline-amorphous mixture) [31,37]. To verify such a hypothesis, the textural properties were assessed through the BET and the BJH methods. Figure 4c shows the $\mathrm{N}_{2}$ adsorption-desorption isotherm characteristic curves of HH-AC-600 and HH-AC-700. Both samples clearly reveal the Type-IV isotherm feature with a Type-H4 hysteresis loop, which can be classified from IUPAC [34], indicating the mesoporous characteristics of the prepared materials $[29,38,39]$. From the BET analysis, the specific surface areas $\left(\mathrm{S}_{\mathrm{sS}}\right)$ of $\mathrm{HH}-\mathrm{AC}-600$ and $\mathrm{HH}-\mathrm{AC}-700$ were determined to be 684 and $936 \mathrm{~m}^{2} / \mathrm{g}$, respectively. Through the BJH analysis (Figure $4 \mathrm{~d}$ ), additionally, the pore surface areas $\left(\mathrm{S}_{\mathrm{ps}}\right)$ of $\mathrm{HH}-\mathrm{AC}-600$ and $\mathrm{HH}-\mathrm{AC}-700$ were calculated to be 204 and $231 \mathrm{~m}^{2} / \mathrm{g}$, respectively. Compared to the HH-AC-600 nanobundles (average pore size $\left(\mathrm{d}_{\mathrm{ap}}\right) \approx 4.52 \mathrm{~nm}$, total pore volume $\left.\left(\mathrm{V}_{\mathrm{tp}}\right) \approx 0.195 \mathrm{~cm}^{3} / \mathrm{g}\right)$, accordingly, the $\mathrm{d}_{\mathrm{ap}}$ and $\mathrm{V}_{\text {tp }}$ values of the HH-AC-700 nanobundles were decreased down to $3.47 \mathrm{~nm}$ and increased up to $0.237 \mathrm{~cm}^{3} / \mathrm{g}$, respectively. These mean that the partially graphitized $\mathrm{HH}-\mathrm{AC}-700$ nanobundles have a higher porosity than that of the amorphous HH-AC-600 nanobundles. Therefore, one can surmise that the microstructural modification (i.e., partial graphitization) of the $\mathrm{HH}-\mathrm{AC}-700$ nanobundles via the higher temperature $\mathrm{KOH}$ activation could lead to the increase in both the textural porosity and the electrical conductivity.

In electrocatalysts, both the enhanced porosity and the increased conductivity play crucial roles for improving the electrochemical reaction. To characterize the electrocatalytic activity of $\mathrm{HH}-\mathrm{AC}-600$ and $\mathrm{HH}-\mathrm{AC}-700$, thus, the $\mathrm{CV}$ properties were measured by using a three-electrode system. As can be seen from Figure 5a,b, both samples exhibit the large CV hysteresis loops at various scan rates of $10-100 \mathrm{mV} / \mathrm{s}$. Such a clear appearance of the typical rectangular CV loops indisputably depicts the effective electrocatalytic behavior occurring inside the electrocatalyst [36,40,41]. Compared to HH-AC-600, however, HH-AC700 show the higher integrated $\mathrm{CV}$ areas and the improved current-voltage responses. This corroborates that the partially graphitized HH-AC-700 nanobundles hold higher porosity and superior electrical conductivity than those of the amorphous HH-AC-600 nanobundles.

(a)

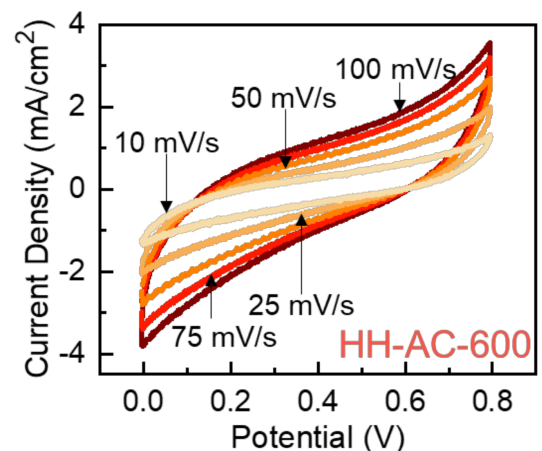

(b)

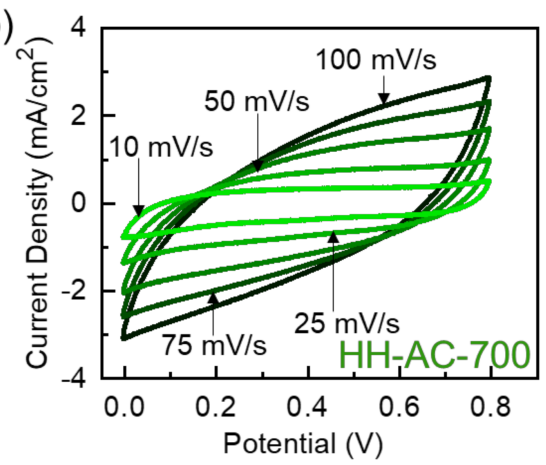

(c)

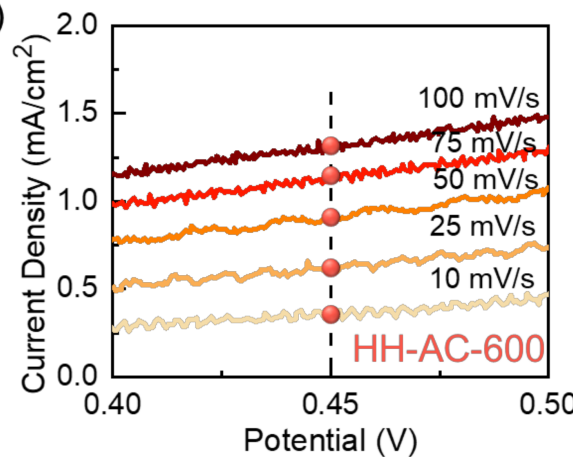

(d)

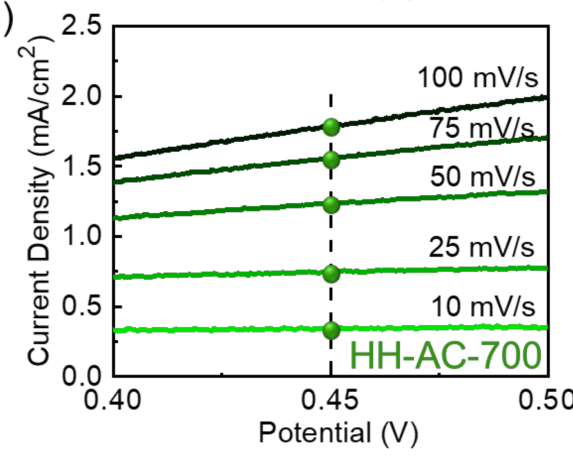

(e)
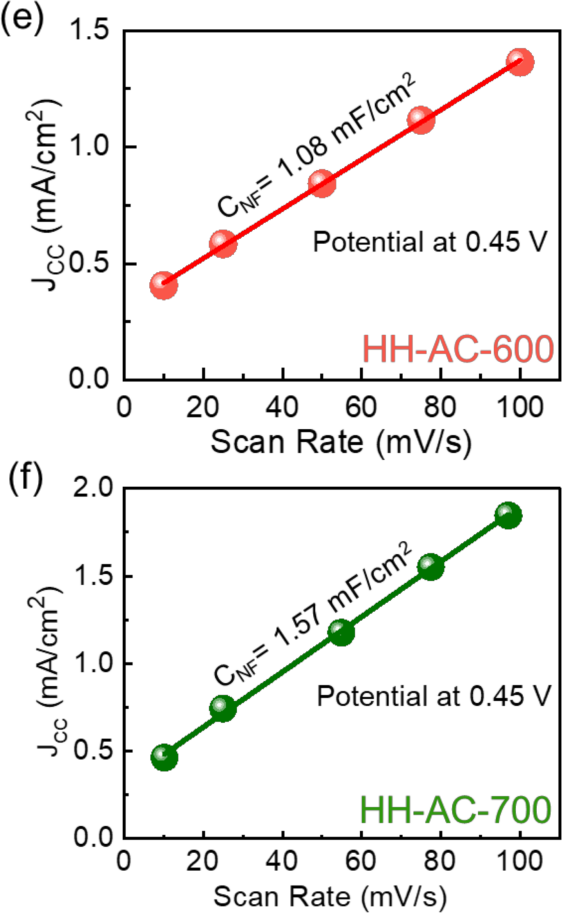

Figure 5. CV curves of the (a) HH-AC-600 and the (b) HH-AC-700 electrodes. CV curves at the Non-Faradaic region near $0.45 \mathrm{~V}$ for the (c) HH-AC-600 and the (d) HH-AC-700 electrodes. JCC as a function of the scan rate for the (e) HH-AC-600 and the (f) HH-AC-700 electrodes. 
The electrocatalytic HER performance is closely related to the electrochemically active surface area (ECSA) of the active electrode material, at which the acidic solutions could react with $\mathrm{AC}$, resulting in the hydrogen production via the chemical reaction of ' $\mathrm{AC}+2 \mathrm{H}^{+}$ $+2 \mathrm{e}^{-} \rightarrow \mathrm{H}_{2}{ }^{\prime}[4,42]$. From the non-Faradic CV region, one can easily estimate the ECSA value by using the following equations $[5,27,43]$ :

$$
\begin{gathered}
E C S A=C_{N F} / C_{E} \\
\mathrm{~J}_{C C}=C_{N F} \times v / A
\end{gathered}
$$

where $\mathrm{C}_{N F}, \mathrm{C}_{E}, \mathrm{~J}_{C C}, v$, and $\mathrm{A}$ are the non-Faradic capacitance, the electrolyte capacitance $\left(0.035 \mathrm{mF} / \mathrm{cm}^{2}\right.$ for $\left.1 \mathrm{M} \mathrm{H}_{2} \mathrm{SO}_{4}\right)$ [44-46], the charging current density, the scan rate, and the electrode area, respectively. Figure $5 \mathrm{c}-\mathrm{f}$ display the non-Faradic $\mathrm{CV}$ curves at $0.4-0.5 \mathrm{~V}$ and their corresponding $\mathrm{J}_{C C}$ values at $0.45 \mathrm{~V}$ as a function of the scan rate. By fitting those experimental data to the above equations, the ECSA values were calculated to be 61 and $89 \mathrm{~cm}^{2}$ for HH-AC-600 and HH-AC-700, respectively, and these values are comparable to and even greater than literature values of other carbonaceous HER electrocatalysts [46,47]. This signifies that the active HH-AC-700 electrode material (i.e., partially graphitized mesoporous $\mathrm{HH}-\mathrm{AC}$ nanobundles) has the improved ion-storage capacity as well as the enhanced electrocatalytic activity compared to the HH-AC-600 electrode.

Based upon all the above results, one may expect the partially graphitized mesoporous $\mathrm{HH}-\mathrm{AC}-700$ nanobundles to act as an effective HER electrocatalyst because the enhanced electrocatalytic activity is one of the most necessary conditions for the high-performance HER electrode [20,23]. To attest this, the electrocatalytic HER performances of the $\mathrm{HH}-$ AC-600 and HH-AC-700 electrodes were examined by measuring the LSV characteristics at $5 \mathrm{mV} / \mathrm{s}$ in $0.5 \mathrm{M} \mathrm{H}_{2} \mathrm{SO}_{4}$. From the obtained polarization LSV curves (Figure 6a), the $\mathrm{HH}-\mathrm{AC}-600$ and HH-AC-700 electrodes were confirmed to have the lower $\eta$ values of 34 and $16 \mathrm{mV}$ at $10 \mathrm{~mA} / \mathrm{cm}^{2}$, respectively.

Furthermore, the samples showed the enhanced electrocatalytic reaction kinetics. Namely, the $S_{T}$ values (Figure $6 \mathrm{~b}$ ) of the HH-AC-600 and HH-AC-700 electrodes were calculated to be 72 and $51 \mathrm{mV} / \mathrm{dec}$, respectively. Compared to the HH-AC-600 electrode, the HH-AC-700 electrode has a superior HER electrocatalytic performance (i.e., lower overpotential: $16 \mathrm{mV}$ at $10 \mathrm{~mA} / \mathrm{cm}^{2}$ and smaller Tafel slope: $51 \mathrm{mV} / \mathrm{dec}$ ) because of its high surface area, large porosity, high electrical conductivity, and electrochemically active surface area. In additional, such an excellent HER activity of HH-AC-700 is comparable to the state-of-the art carbonaceous HER electrocatalyst (i.e., HH-derived N- and S-codoped porous AC [24]) and is far superior to any others ever reported (see Table 1). Figure 6c displays the chronopotentiometric characteristics of the HH-AC-600 and HH-AC-700 electrodes. The multiple chronopotentiometric characteristics reveal that the HH-AC-700 electrode has a smaller overpotential at each current density than that of the HH-AC600 electrode. Additionally, the HH-AC-700 electrode exhibits the stable and long-term HER durability, compared to the HH-AC-600 electrode (Figure 6d). After the durability test, the overpotential was further reduced because the electrical current might galvanize the material. Furthermore, the LSV curves before and after the durability test clearly demonstrated their outstanding electrochemical stability for the HER performance in the $\mathrm{H}_{2} \mathrm{SO}_{4}$ solution (Figure $\mathrm{S} 2$ ). 
(a)

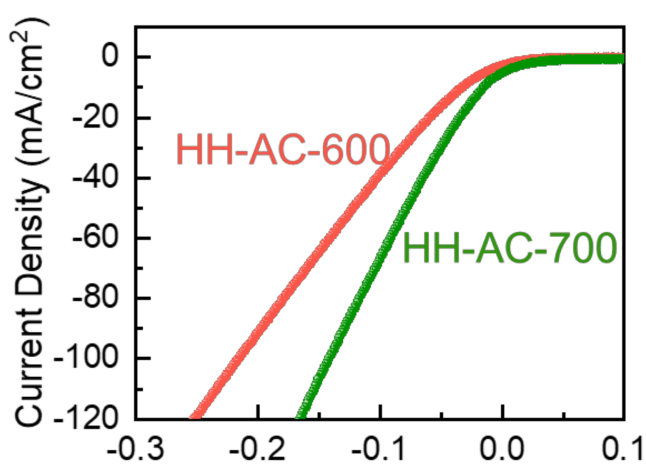

(c)

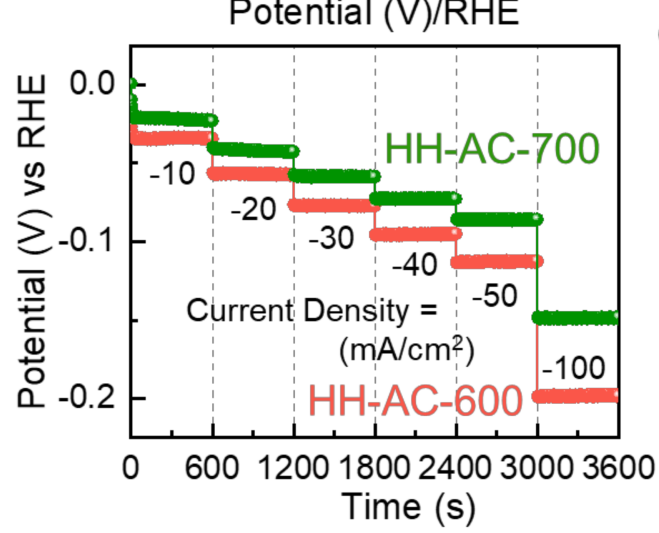

(b)

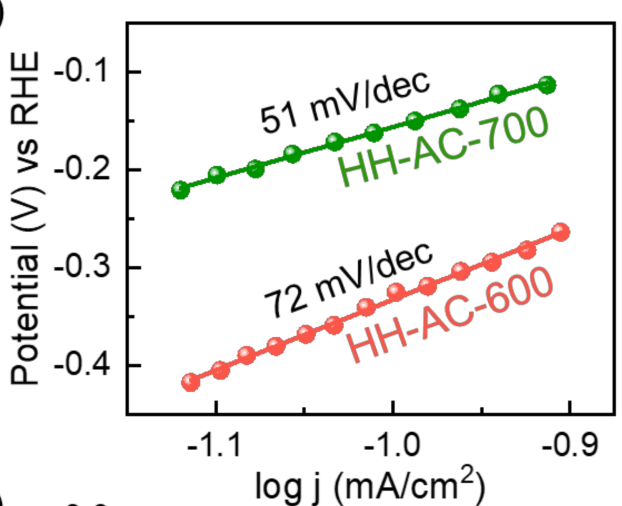

(d)

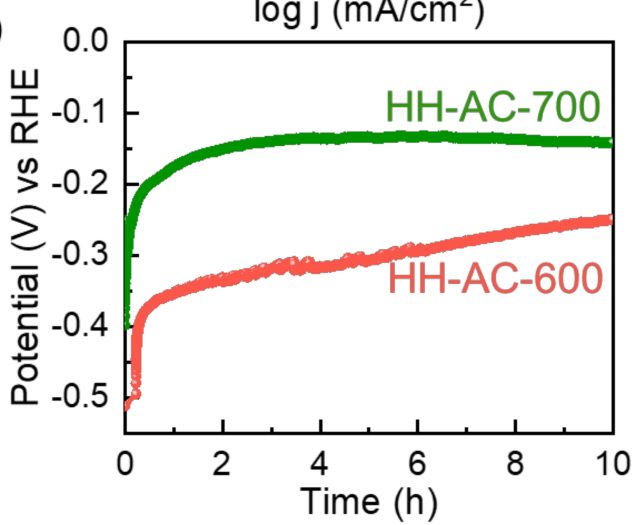

Figure 6. (a) LSV polarization curves, (b) Tafel curves, (c) multi-chronopotentiometric profiles at various current densities (from -10 to $-100 \mathrm{~mA} / \mathrm{cm}^{2}$ ), and (d) time-dependent HER durability for the HH-AC-600 and the HH-AC-700 electrodes.

Table 1. Comparison of the HER performances for the proposed HH-AC-600 and HH-AC-700 with other carbonaceous electrocatalysts reported in previous works.

\begin{tabular}{|c|c|c|c|c|}
\hline Catalyst & $\begin{array}{l}\text { Overpotential } \\
\eta(\mathrm{mV})\end{array}$ & $\begin{array}{c}\text { Tafel Slope } \\
S_{T}(\mathrm{~m} V / d e c)\end{array}$ & Electrolytes & Reference \\
\hline HH-AC-700 layered nanobundles & 16 & 51 & $0.5 \mathrm{M} \mathrm{H}_{2} \mathrm{SO}_{4}$ & This Work \\
\hline HH-AC-600 nanobundles & 34 & 72 & $0.5 \mathrm{M} \mathrm{H}_{2} \mathrm{SO}_{4}$ & This Work \\
\hline $\mathrm{N}$ - and S-codoped graphene & 276 & 81 & $0.5 \mathrm{M} \mathrm{H}_{2} \mathrm{SO}_{4}$ & [11] \\
\hline $\mathrm{N}$ - and P-codoped graphene & 106 & 67.3 & $0.5 \mathrm{M} \mathrm{H}_{2} \mathrm{SO}_{4}$ & [12] \\
\hline Defective AC & 334 & 66 & $0.5 \mathrm{M} \mathrm{H}_{2} \mathrm{SO}_{4}$ & [13] \\
\hline N-doped AC & 80 & 75 & $0.5 \mathrm{M} \mathrm{H}_{2} \mathrm{SO}_{4}$ & [14] \\
\hline Nanoporous AC & 380 & 85 & $0.5 \mathrm{M} \mathrm{H}_{2} \mathrm{SO}_{4}$ & [15] \\
\hline $\mathrm{N}$ - and S-codoped AC & 450 & 163 & $1 \mathrm{M} \mathrm{KOH}$ & [16] \\
\hline $\mathrm{N}$ - and S-codoped CNT * & 450 & 133 & $1 \mathrm{M} \mathrm{KOH}$ & [18] \\
\hline Ni-NiO-CNT composite & 276 & 94 & $1 \mathrm{M} \mathrm{H}_{2} \mathrm{SO}_{4}$ & [19] \\
\hline Activated CNT * & 225 & 71 & $0.5 \mathrm{M} \mathrm{H}_{2} \mathrm{SO}_{4}$ & [20] \\
\hline N-doped porous carbon & 179 & 98 & $1 \mathrm{M} \mathrm{KOH}$ & [23] \\
\hline $\mathrm{N}$ - and S-codoped porous carbon & 12 & 57.4 & $0.5 \mathrm{M} \mathrm{H}_{2} \mathrm{SO}_{4}$ & [24] \\
\hline N-doped carbon fiber & 150 & 89 & $0.5 \mathrm{M} \mathrm{H}_{2} \mathrm{SO}_{4}$ & [25] \\
\hline
\end{tabular}

${ }^{*}$ Note. CNT: carbon nanotube.

To elucidate the kinetics of the excellent HER activity, the EIS measurements were conducted before and after the durability test. As shown in Figure 7a,b, regardless of the durability test, both electrodes reveal only a linear EIS feature, arising from the effective electrolyte diffusion into the electrode [48,49]. Here, one needs to focus on the absence of semicircles at the high frequency region. Since the semicircle is associated with the charge transfer resistance $[25,50]$, no semicircle in the EIS spectra infers that the HER catalyst has a high electronic conductivity and a high ionic diffusivity $[5,27]$. The series resistance 
$\left(\mathrm{R}_{\mathrm{s}} \approx 1 \Omega\right.$ ) value is smaller for the HH-AC-700 nanobundles than that for the HH-AC-600 nanobundles $\left(\mathrm{R}_{\mathrm{S}} \approx 2.4 \Omega\right.$ ). Consequently, the partial graphitization of the HH-AC-700 nanobundles gives rise to the increases in both the textural porosity and the electrical conductivity and eventually leads to the superior HER activity via the enhanced ionic diffusion and the effective electronic charge transport.
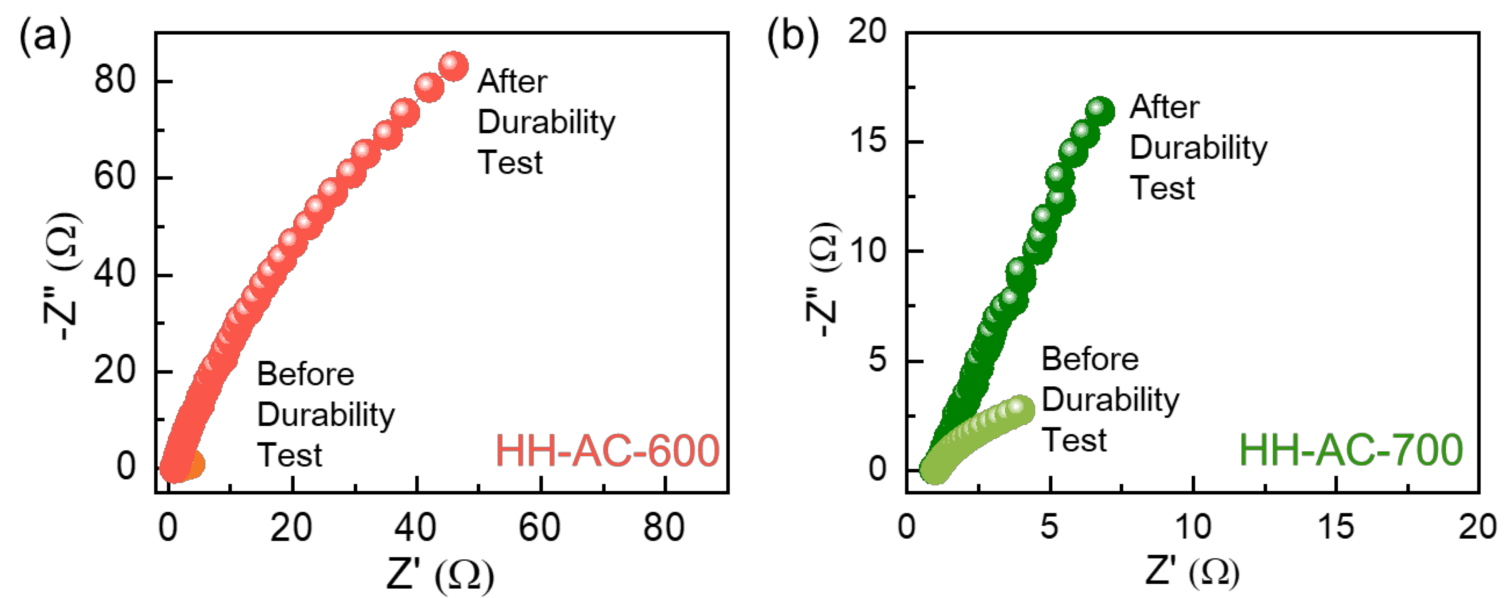

Figure 7. Nyquist plots of the (a) HH-AC-600 and the (b) HH-AC-700 electrodes before and after the durability test.

\section{Conclusions}

The $\mathrm{HH}-\mathrm{AC}$ nanobundles were effectively synthesized by the $\mathrm{KOH}$ activation of the biomass $\mathrm{HH}$ carbonaceous resources. The $600^{\circ} \mathrm{C}$-activated $\mathrm{HH}$-AC nanobundles showed the amorphous phase, whereas the $700{ }^{\circ} \mathrm{C}$-activated $\mathrm{HH}$-AC nanobundles displayed the partially graphitized crystallite textures. Since the partial graphitization of AC increases both the textural porosity (average pore size $\approx 3.47 \mathrm{~nm}$, total pore volume $\approx 0.237 \mathrm{~cm}^{3} / \mathrm{g}$ ) and the electrical conductivity (series resistance $\approx 1 \Omega$ ), the $700{ }^{\circ} \mathrm{C}$-activated $\mathrm{HH}$-AC sample showed the superior HER activity with an extremely low overpotential $(\approx 16 \mathrm{mV}$ at $10 \mathrm{~mA} / \mathrm{cm}^{2}$ in $\left.0.5 \mathrm{M} \mathrm{H}_{2} \mathrm{SO}_{4}\right)$ and a very small Tafel slope $(\approx 51 \mathrm{mV} / \mathrm{dec})$. The results suggest that the partially graphitized nanobundles can be utilized as an excellent HER electrocatalyst for future green hydrogen-energy technology.

Supplementary Materials: The following supporting information can be downloaded at: https: / / www.mdpi.com/article/10.3390/nano12030531/s1, Figure S1: EDX spectra of the (a) HH-AC-600 and (b) HH-AC-700 samples. The small amounts of Pt arose from the ultrathin Pt conducting layer, which had been coated on the samples for better visualization of the FE-SEM images, Figure S2: LSV curves of the (a) HH-AC-600 and (b) HH-AC-700 electrodes for HER before and after the durability test.

Author Contributions: S.S.: methodology, investigation, data validation, and writing-original draft. D.H.S.: investigation and data curation. S.L.: conceptualization, supervision, funding acquisition, resources, and writing-review and editing. All authors have read and agreed to the published version of the manuscript.

Funding: This research was supported by the National Research Foundation (NRF) of Korea through the Basic Science Research Programs (2016R1A6A1A03012877 and 2019R1A2C1085448) funded by the Korean Government.

Institutional Review Board Statement: Not applicable.

Informed Consent Statement: Not applicable.

Data Availability Statement: The data presented in this study are available on request from the corresponding author. 
Conflicts of Interest: The authors declare that they have no known competing financial interests or personal relationships that could have appeared to influence the work reported in this paper.

\section{References}

1. Li, W.; Liu, Y.; Wu, M.; Feng, X.; Redfern, S.A.T.; Shang, Y.; Yong, X.; Feng, T.; Wu, K.; Liu, Z.; et al. Carbon-Quantum-DotsLoaded Ruthenium Nanoparticles as an Efficient Electrocatalyst for Hydrogen Production in Alkaline Media. Adv. Mater. 2018, 30, 1800676. [CrossRef] [PubMed]

2. Sapountzi, F.M.; Gracia, J.M.; Weststrate, C.J.; Fredriksson, H.O.A.; Niemantsverdriet, J.W. Electrocatalysts for the generation of hydrogen, oxygen and synthesis gas. Prog. Energy Combust. Sci. 2017, 58, 1-35. [CrossRef]

3. Zhang, M.; Guan, J.; Tu, Y.; Chen, S.; Wang, Y.; Wang, S.; Yu, L.; Ma, C.; Deng, D.; Bao, X. Highly efficient H2 production from H2S via a robust graphene-encapsulated metal catalyst. Energy Environ. Sci. 2020, 13, 119-126. [CrossRef]

4. Jin, H.; Guo, C.; Liu, X.; Liu, J.; Vasileff, A.; Jiao, Y.; Zheng, Y.; Qiao, S.-Z. Emerging Two-Dimensional Nanomaterials for Electrocatalysis. Chem. Rev. 2018, 118, 6337-6408. [CrossRef]

5. Sekar, S.; Aqueel Ahmed, A.T.; Pawar, S.M.; Lee, Y.; Im, H.; Kim, D.Y.; Lee, S. Enhanced water splitting performance of biomass activated carbon-anchored $\mathrm{WO}_{3}$ nanoflakes. Appl. Surf. Sci. 2020, 508, 145127. [CrossRef]

6. Wang, S.; Lu, A.; Zhong, C.-J. Hydrogen production from water electrolysis: Role of catalysts. Nano Converg. 2021, 8, 4. [CrossRef]

7. Xu, S.; Gong, S.; Jiang, H.; Shi, P.; Fan, J.; Xu, Q.; Min, Y. Z-scheme heterojunction through interface engineering for broad spectrum photocatalytic water splitting. Appl. Catal. B Environ. 2020, 267, 118661. [CrossRef]

8. Jaleh, B.; Nasrollahzadeh, M.; Nasri, A.; Eslamipanah, M.; Moradi, A.; Nezafat, Z. Biopolymer-derived (nano)catalysts for hydrogen evolution via hydrolysis of hydrides and electrochemical and photocatalytic techniques: A review. Int. J. Biol. Macromol. 2021, 182, 1056-1090. [CrossRef]

9. Wang, Q.; Guo, R.; Wang, Z.; Shen, D.; Yu, R.; Luo, K.; Wu, C.; Gu, S. Progress in carbon-based electrocatalyst derived from biomass for the hydrogen evolution reaction. Fuel 2021, 293, 120440. [CrossRef]

10. Ghosh, S.; Basu, R.N. Multifunctional nanostructured electrocatalysts for energy conversion and storage: Current status and perspectives. Nanoscale 2018, 10, 11241-11280. [CrossRef]

11. Ito, Y.; Cong, W.; Fujita, T.; Tang, Z.; Chen, M. High Catalytic Activity of Nitrogen and Sulfur Co-Doped Nanoporous Graphene in the Hydrogen Evolution Reaction. Angew. Chem. Int. Ed. 2015, 54, 2131-2136. [CrossRef] [PubMed]

12. Wu, H.; Chen, Z.; Wang, Y.; Cao, E.; Xiao, F.; Chen, S.; Du, S.; Wu, Y.; Ren, Z. Regulating the allocation of N and P in codoped graphene via supramolecular control to remarkably boost hydrogen evolution. Energy Environ. Sci. 2019, 12, 2697-2705. [CrossRef]

13. Yan, X.; Jia, Y.; Odedairo, T.; Zhao, X.; Jin, Z.; Zhu, Z.; Yao, X. Activated carbon becomes active for oxygen reduction and hydrogen evolution reactions. Chem. Commun. 2016, 52, 8156-8159. [CrossRef] [PubMed]

14. Saravanan, K.R.A.; Prabu, N.; Sasidharan, M.; Maduraiveeran, G. Nitrogen-self doped activated carbon nanosheets derived from peanut shells for enhanced hydrogen evolution reaction. Appl. Surf. Sci. 2019, 489, 725-733. [CrossRef]

15. Prabu, N.; Kesavan, T.; Maduraiveeran, G.; Sasidharan, M. Bio-derived nanoporous activated carbon sheets as electrocatalyst for enhanced electrochemical water splitting. Int. J. Hydrog. Energy 2019, 44, 19995-20006. [CrossRef]

16. Zhao, Y.-M.; Ren, T.-Z.; Yuan, Z.-Y.; Bandosz, T.J. Activated carbon with heteroatoms from organic salt for hydrogen evolution reaction. Micropor. Mesopor. Mat. 2020, 297, 110033. [CrossRef]

17. Akyüz, D.; Keskin, B.; Şahintürk, U.; Koca, A. Electrocatalytic hydrogen evolution reaction on reduced graphene oxide electrode decorated with cobaltphthalocyanine. Appl. Catal. B 2016, 188, 217-226. [CrossRef]

18. Qu, K.; Zheng, Y.; Jiao, Y.; Zhang, X.; Dai, S.; Qiao, S.-Z. Polydopamine-Inspired, Dual Heteroatom-Doped Carbon Nanotubes for Highly Efficient Overall Water Splitting. Adv. Energy Mater. 2017, 7, 1602068. [CrossRef]

19. Elizabeth, I.; Nair, A.K.; Singh, B.P.; Gopukumar, S. Multifunctional Ni-NiO-CNT Composite as High Performing Free Standing Anode for Li Ion Batteries and Advanced Electro Catalyst for Oxygen Evolution Reaction. Electrochim. Acta 2017, 230, 98-105. [CrossRef]

20. Cui, W.; Liu, Q.; Cheng, N.; Asiri, A.M.; Sun, X. Activated carbon nanotubes: A highly-active metal-free electrocatalyst for hydrogen evolution reaction. Chem. Commun. 2014, 50, 9340-9342. [CrossRef]

21. Wang, J.; Li, H.; Meng, S.; Ye, X.; Fu, X.; Chen, S. Controlled synthesis of Sn-based oxides via a hydrothermal method and their visible light photocatalytic performances. RSC Adv. 2017, 7, 27024-27032. [CrossRef]

22. Shinde, S.S.; Sami, A.; Lee, J.-H. Electrocatalytic hydrogen evolution using graphitic carbon nitride coupled with nanoporous graphene co-doped by S and Se. J. Mater. Chem. A 2015, 3, 12810-12819. [CrossRef]

23. Sathiskumar, C.; Ramakrishnan, S.; Vinothkannan, M.; Rhan Kim, A.; Karthikeyan, S.; Yoo, D.J. Nitrogen-Doped Porous Carbon Derived from Biomass Used as Trifunctional Electrocatalyst toward Oxygen Reduction, Oxygen Evolution and Hydrogen Evolution Reactions. Nanomaterials 2020, 10, 76. [CrossRef] [PubMed]

24. Liu, X.; Zhou, W.; Yang, L.; Li, L.; Zhang, Z.; Ke, Y.; Chen, S. Nitrogen and sulfur co-doped porous carbon derived from human hair as highly efficient metal-free electrocatalysts for hydrogen evolution reactions. J. Mater. Chem. A 2015, 3, 8840-8846. [CrossRef]

25. Liu, Y.; Hu, M.; Xu, W.; Wu, X.; Jiang, J. Catalytically Active Carbon from Cattail Fibers for Electrochemical Reduction Reaction. Front. Chem. 2019, 7, 786. [CrossRef]

26. Wang, J.; Kong, H.; Zhang, J.; Hao, Y.; Shao, Z.; Ciucci, F. Carbon-based electrocatalysts for sustainable energy applications. Prog. Mater. Sci. 2021, 116, 100717. [CrossRef] 
27. Sekar, S.; Kim, D.Y.; Lee, S. Excellent Oxygen Evolution Reaction of Activated Carbon-Anchored NiO Nanotablets Prepared by Green Routes. Nanomaterials 2020, 10, 1382. [CrossRef]

28. Atif, M.; Farid, M.Q.; Ahmad, S.A.; Abdul Karim, R.; Hussain, A.; Rabbani, F.; Bongiovanni, R. Electrochemical Evaluation of Human Hair Derived Carbon Particles. ECS J. Solid State Sci. Technol. 2020, 9, 051003. [CrossRef]

29. Sankar, S.; Ahmed, A.T.A.; Inamdar, A.I.; Im, H.; Im, Y.B.; Lee, Y.; Kim, D.Y.; Lee, S. Biomass-derived ultrathin mesoporous graphitic carbon nanoflakes as stable electrode material for high-performance supercapacitors. Mater. Des. 2019, 169, 107688. [CrossRef]

30. Manasa, P.; Lei, Z.J.; Ran, F. Biomass Waste Derived Low Cost Activated Carbon from Carchorus Olitorius (Jute Fiber) as Sustainable and Novel Electrode Material. J. Energy Storage 2020, 30, 101494. [CrossRef]

31. Sekar, S.; Aqueel Ahmed, A.T.; Inamdar, A.I.; Lee, Y.; Im, H.; Kim, D.Y.; Lee, S. Activated carbon-decorated spherical silicon nanocrystal composites synchronously-derived from rice husks for anodic source of lithium-ion battery. Nanomaterials 2019, 9, 1055. [CrossRef] [PubMed]

32. Qian, W.; Sun, F.; Xu, Y.; Qiu, L.; Liu, C.; Wang, S.; Yan, F. Human hair-derived carbon flakes for electrochemical supercapacitors. Energy Environ. Sci. 2014, 7, 379-386. [CrossRef]

33. Zhu, Y.; Murali, S.; Stoller, M.D.; Ganesh, K.J.; Cai, W.; Ferreira, P.J.; Pirkle, A.; Wallace, R.M.; Cychosz, K.A.; Thommes, M.; et al Carbon-Based Supercapacitors Produced by Activation of Graphene. Science 2011, 332, 1537-1541. [CrossRef] [PubMed]

34. Sekar, S.; Aqueel Ahmed, A.T.; Kim, D.Y.; Lee, S. One-Pot Synthesized Biomass C-Si Nanocomposites as an Anodic Material for High-Performance Sodium-Ion Battery. Nanomaterials 2020, 10, 1728. [CrossRef]

35. Sekar, S.; Lee, Y.; Kim, D.Y.; Lee, S. Substantial LIB anode performance of graphitic carbon nanoflakes derived from biomass green-tea waste. Nanomaterials 2019, 9, 871. [CrossRef]

36. Sankar, S.; Lee, H.; Jung, H.; Kim, A.; Aqueel Ahmed, A.T.; Inamdar, A.I.; Kim, H.; Lee, S.; Im, H.; Kim, D.Y. Ultrathin graphene nanosheets derived from rice husks for sustainable supercapacitor electrodes. New J. Chem. 2017, 41, 13792-13797. [CrossRef]

37. Sekar, S.; Lee, S.; Vijayarengan, P.; Kalirajan, K.M.; Santhakumar, T.; Sekar, S.; Sadhasivam, S. Upcycling of Wastewater via Effective Photocatalytic Hydrogen Production Using $\mathrm{MnO}_{2}$ Nanoparticles-Decorated Activated Carbon Nanoflakes. Nanomaterials 2020, 10, 1610. [CrossRef]

38. Sekar, S.; Lee, S.; Kim, D.Y.; Preethi, V.; Kalirajan, K.M.; Sutha, S.; Saravanan, S.; Therli, A.; Roy, M.; Jagannathan, K. Biomass activated carbon-decorated spherical $\beta-\mathrm{Ni}(\mathrm{OH})_{2}$ nanoparticles for enhanced hydrogen production from sulphide wastewater. $J$. Water Process. Eng. 2020, 38, 101669. [CrossRef]

39. Ahmed, M.J.; Islam, M.A.; Asif, M.; Hameed, B.H. Human hair-derived high surface area porous carbon material for the adsorption isotherm and kinetics of tetracycline antibiotics. Bioresour. Technol. 2017, 243, 778-784. [CrossRef]

40. Rajagopal, R.R.; Aravinda, L.S.; Rajarao, R.; Bhat, B.R.; Sahajwalla, V. Activated carbon derived from non-metallic printed circuit board waste for supercapacitor application. Electrochim. Acta 2016, 211, 488-498. [CrossRef]

41. Eleri, O.E.; Azuatalam, K.U.; Minde, M.W.; Trindade, A.M.; Muthuswamy, N.; Lou, F.; Yu, Z. Towards high-energy-density supercapacitors via less-defects activated carbon from sawdust. Electrochim. Acta 2020, 362, 137152. [CrossRef]

42. Yu, A.; Kim, S.Y.; Lee, C.; Kim, M.H.; Lee, Y. Boosted Electron-Transfer Kinetics of Hydrogen Evolution Reaction at Bimetallic RhCo Alloy Nanotubes in Acidic Solution. ACS Appl. Mater. Interfaces 2019, 11, 46886-46893. [CrossRef] [PubMed]

43. Aqueel Ahmed, A.T.; Pawar, S.M.; Inamdar, A.I.; Kim, H.; Im, H. A Morphologically Engineered Robust Bifunctional CuCo2O4 Nanosheet Catalyst for Highly Efficient Overall Water Splitting. Adv. Mater. Interfaces 2020, 7, 1901515. [CrossRef]

44. McCrory, C.C.L.; Jung, S.; Peters, J.C.; Jaramillo, T.F. Benchmarking heterogeneous electrocatalysts for the oxygen evolution reaction. J. Am. Chem. Soc. 2013, 135, 16977-16987. [CrossRef] [PubMed]

45. Ahmed, A.T.A.; Pawar, S.M.; Inamdar, A.I.; Im, H.; Kim, H. Fabrication of FeO@CuCo2S4 multifunctional electrode for ultrahighcapacity supercapacitors and efficient oxygen evolution reaction. Int. J. Energy Res. 2020, 44, 1798-1811. [CrossRef]

46. Schonvogel, D.; Nowotny, M.; Woriescheck, T.; Multhaupt, H.; Wagner, P.; Dyck, A.; Agert, C.; Wark, M. Hydrothermal Carbonization-Derived Carbon from Waste Biomass as Renewable Pt Support for Fuel Cell Applications: Role of Carbon Activation. Energy Technol. 2019, 7, 1900344. [CrossRef]

47. Ren, H.; Pan, Y.; Sorrell, C.C.; Du, H. Assessment of electrocatalytic activity through the lens of three surface area normalization techniques. J. Mater. Chem. A 2020, 8, 3154-3159. [CrossRef]

48. Ullah, N.; Zhao, W.; Lu, X.; Oluigbo, C.J.; Shah, S.A.; Zhang, M.; Xie, J.; Xu, Y. In situ growth of M-MO (M = Ni, Co) in 3D graphene as a competent bifunctional electrocatalyst for OER and HER. Electrochim. Acta 2019, 298, 163-171. [CrossRef]

49. Hoang, V.C.; Dinh, K.N.; Gomes, V.G. Hybrid Ni/NiO composite with N-doped activated carbon from waste cauliflower leaves: A sustainable bifunctional electrocatalyst for efficient water splitting. Carbon 2020, 157, 515-524. [CrossRef]

50. Qu, K.; Zheng, Y.; Zhang, X.; Davey, K.; Dai, S.; Qiao, S.Z. Promotion of Electrocatalytic Hydrogen Evolution Reaction on Nitrogen-Doped Carbon Nanosheets with Secondary Heteroatoms. ACS Nano 2017, 11, 7293-7300. [CrossRef] 